\title{
Performance Monitoring System for Precision Planter Based on MSP430-CT171
}

\author{
Lianming Xia, Xiangyou Wang ${ }^{*}$, Duanyang Geng, and Qingfeng Zhang \\ School of Agricultural and Food Engineering, Shandong University of Technology \\ Zibo, Shandong, China \\ xiawj655@163.com, wxy@sdut.edu.cn, dygxt@sdut.edu.cn, \\ zhangqingfeng1844@163.com
}

\begin{abstract}
Based on full consideration of the working conditions in the filed, a monitoring system for precision planter was designed using the technology of sensor, single-chip Microcomputer and wireless transmission. In this system, photoelectric sensor and MSP430 were used to detect the performance of the seeder-metering device and process the data respectively. It mainly detected the miss index, multiple index, seeding amount, seeding rate, the plant spacing and other performance parameters. In the sound-light alarm system, a indicator light was used to show the fault type and location, then the detected data and fault can be displayed on the LED. In order to acquire and analyze the data at realtime, a wireless transmission system based on Bluetooth was designed. FSBT485Abluetooth module was used to communicate with the host computer. To ensure the uniformity of drilling and sowing, a stepping motor was used to control the seeding rate in the laboratory. The results showed that reliability of the sound-light alarm system was $100 \%$ and the photoelectric sensor could detect more than $95 \%$ seeds passed it.
\end{abstract}

Keywords: Monitoring system, Precision planter, photoelectric sensor, Singlechip microcomputer, Bluetooth technology, Stepper motor.

\section{Introduction}

The seed-metering device is the core component of precision planter. Precision planting is defined as the placement of single seeds in the soil at desired plants spacing $[1,2]$. The seed-metering devices which are often used can be divided into two categories such as mechanical and pneumatic. Whether either seed-metering device is used, the flow process of the seeds is all invisible. So, we can not determine whether the sowing quality is good or not only by vision and hearing. With the sensors, the intelligent monitoring system for precision planter can monitor the sowing process and alarm in different ways. Once the faults happen, the system can tell the location and kind of the faults timely. So, it is of great economic and practical significance for studying the monitoring technology for precision seed-metering device. By far, we could monitor the metering quality by the methods such as manual

Corresponding author. 
monitoring, photoelectric effect, piezoelectric effect and high-speed photography [3, 4 and 5]. Based on the technologies of single-chip microcomputer, sensor, information and virtual instrument, the monitoring systems for precision planter have gained great progress in recent years. In this paper, a performance monitoring system for precision planter based on MSP430 is designed.

\section{Structure and Working Principle of the System}

In this system, the infrared photoelectric sensor is installed near the furrow opener. In order to better guarantee the accuracy of monitoring, three or four photoelectric sensors are installed on the seed tube symmetrically and evenly. Every seed tube represents one row and an indicator light is used to show the performance of the planter $[6,7]$. When the pulse signals produced when the seeds pass through the sensor are transmitted to single-chip microcomputer, it decides whether the pulse signals are normal or not. Sound and light alarm signals will be sent out when seeds absence, the grain box is empty and the metering devices are blocked. The indicator light is extinct when the planter is at normal operation and the light will blink when there is something wrong with the planter such as seeds absence [8]. The schematic is showed in the Fig.1.

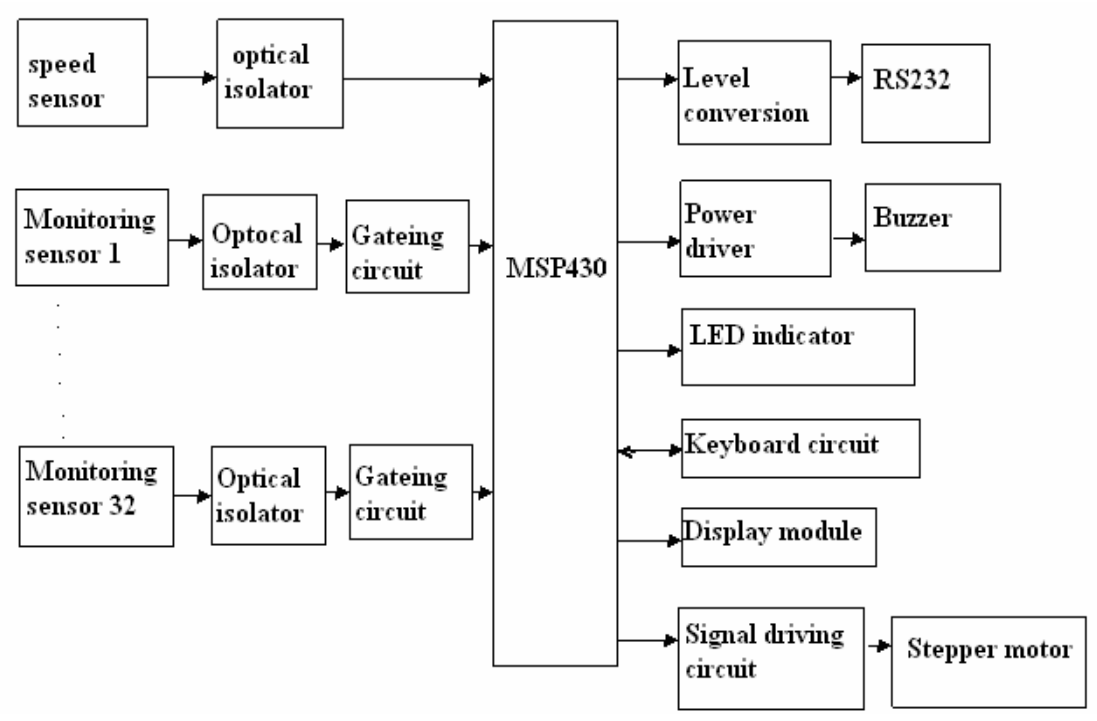

Fig. 1. Structure of the monitoring system

\section{Design of the Monitoring System}

The monitoring system is mainly composed of photoelectric sensor, alarm system, display system and wireless data transmission system. 


\subsection{Design of Power Circuit}

In order to work under normal conditions, MSP430 must be supplied with 3.3 voltages by the system. Because of the unstable voltage of the $12 \mathrm{v}$ level on the precision planter, it is necessary to be converted to $3.3 \mathrm{v}$. The power circuit is showed in Fig. 2.
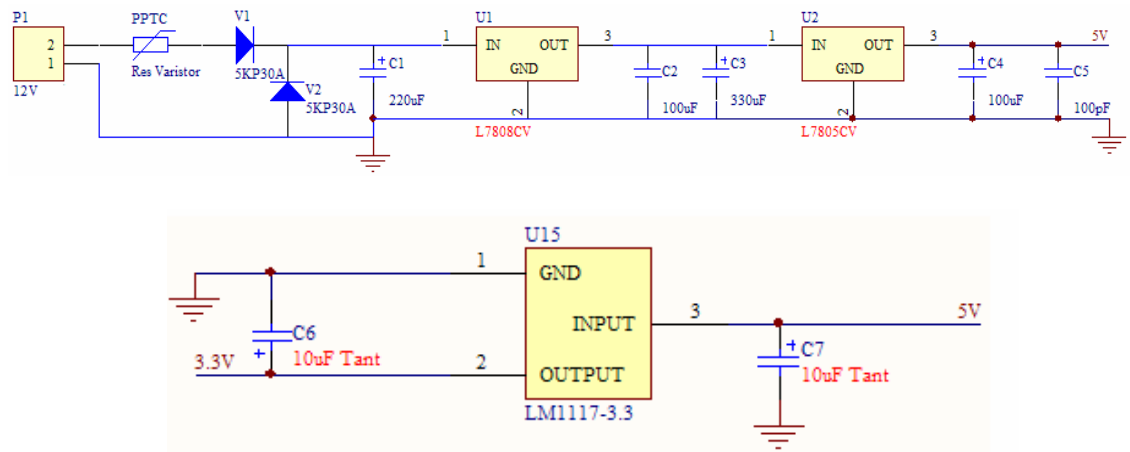

Fig. 2. Power circuit of MSP430

\subsection{Circuits of the Sensors}

The photoelectric sensor system is composed of photoelectric coupled device and LM339. The coupled device is composed of infrared LED and phototransistor. LM339 is the integrated circuit of four voltage comparator. When the seeds pass through the range covered by the LED, the phototransistor will close and up level is output. Then the level will be low after filter by LM339.

The situation is contrary when there is no seed passing through the range covered by the LED. The output pulse signals are connected to port $\mathrm{P} 2$ which is the external interrupt of MSP430 [9]. The circuit of the photoelectric sensor is showed in Fig.3.

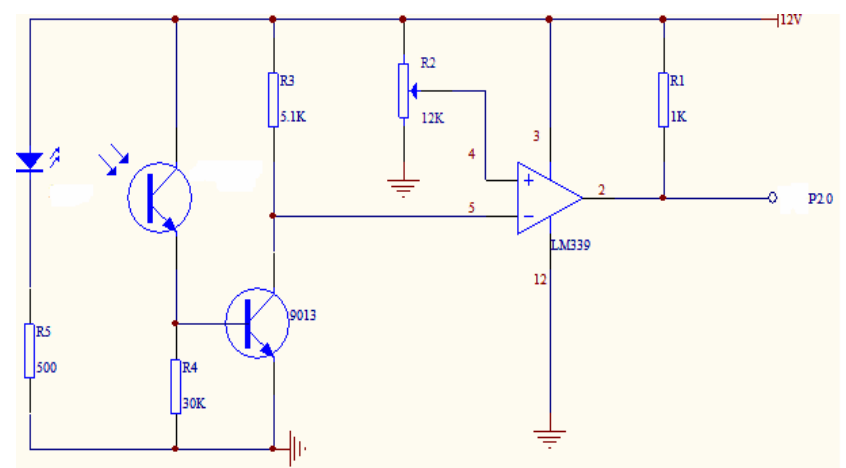

Fig. 3. Circuit of the photoelectric sensor 


\subsection{Design of the Sound and Light Alarm Circuit}

The system will alarm when the grain box is empty, the seed tube or the furrow opener is blocked by debris and the metering devices stop working. At the same time, the indicator light will blink to tell the driver that there is something wrong with the planter. The circuits are showed in Fig. 4 and Fig. 5.

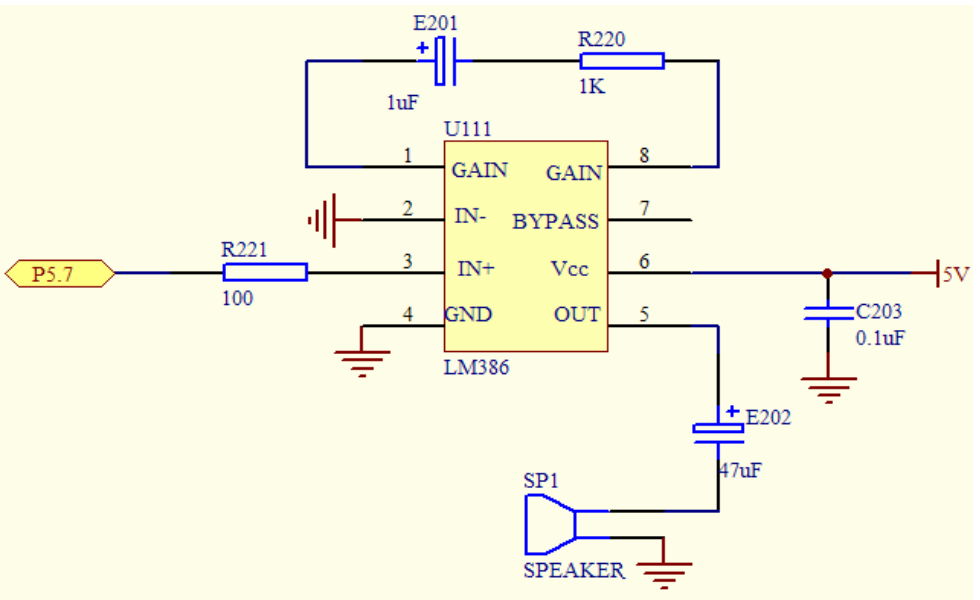

Fig. 4. The circuit of sound alarm

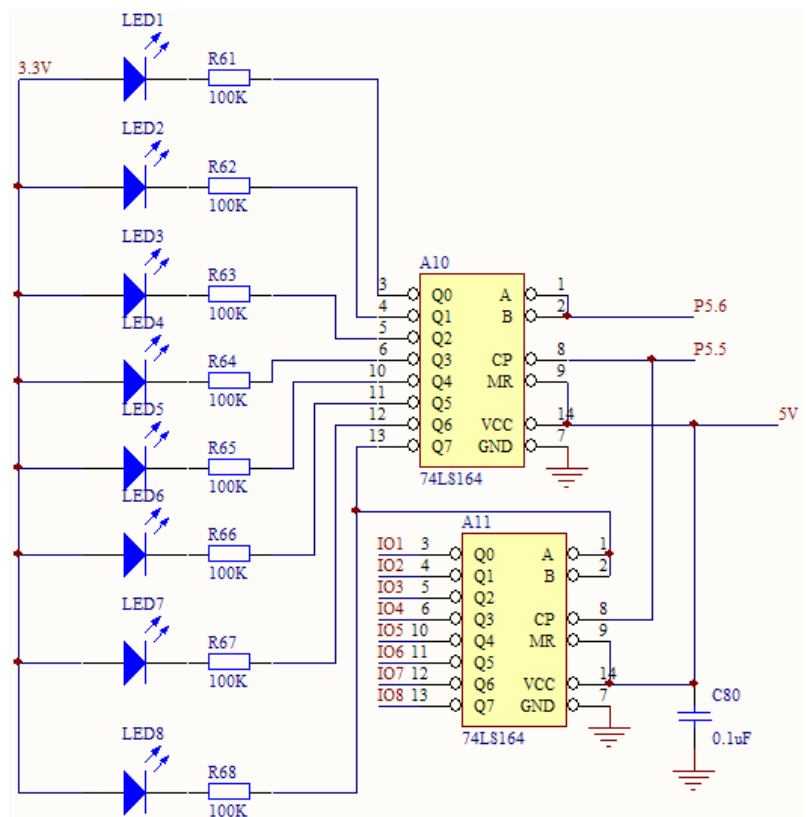

Fig. 5. The circuit of light alarm 


\subsection{The Circuit of Display}

The function of the display circuit is to show the data and indicate faults. A LCD with better backlight effect is used in order to display the screen contents clearly. In this system, we choose LMC240128ZK as the display module. The LCD module has 8-bit parallel data interface and it is directly connected to the pin of MSP430. The pins of the module can be divided into data pin, control pin and power pin. Its circuit is showed in Fig. 6.

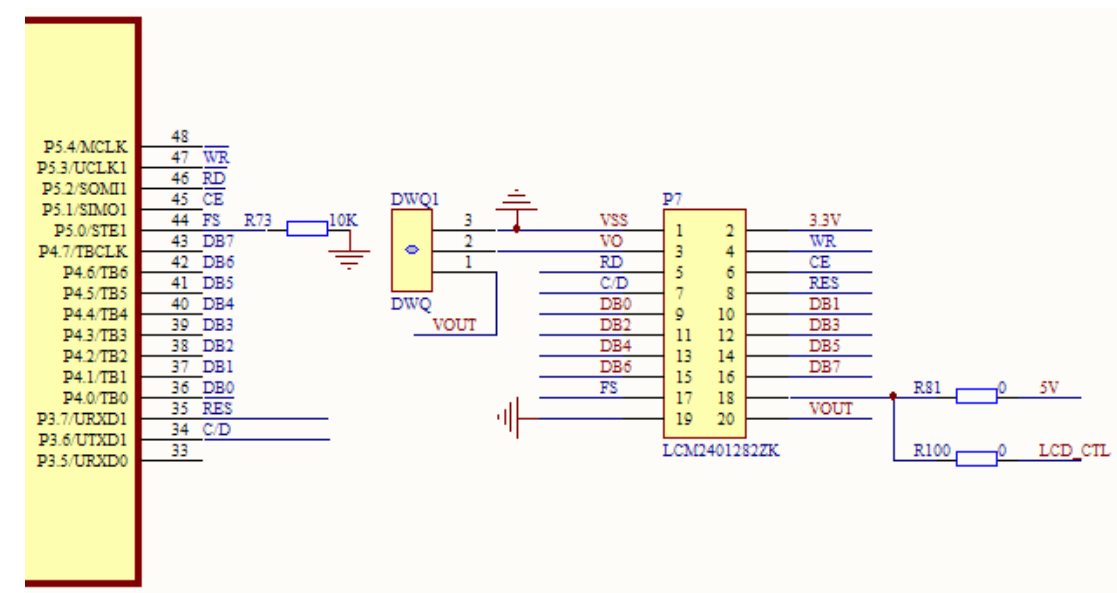

Fig. 6. The circuit of display

\subsection{The Wireless Data Transmission System}

In this paper, a wireless data transmission system based on Bluetooth is used because of its high efficiency, reliability and security. The system is composed of signal collection and transmission units, MSP430, the hopper computer and the Bluetooth communication device. The key of the system is to choose the Bluetooth module. In this system, the Bluetooth module used is FS-BT485A serial adapter [10, 11]. The block diagram of the wireless data transmission system is showed in Fig. 7.

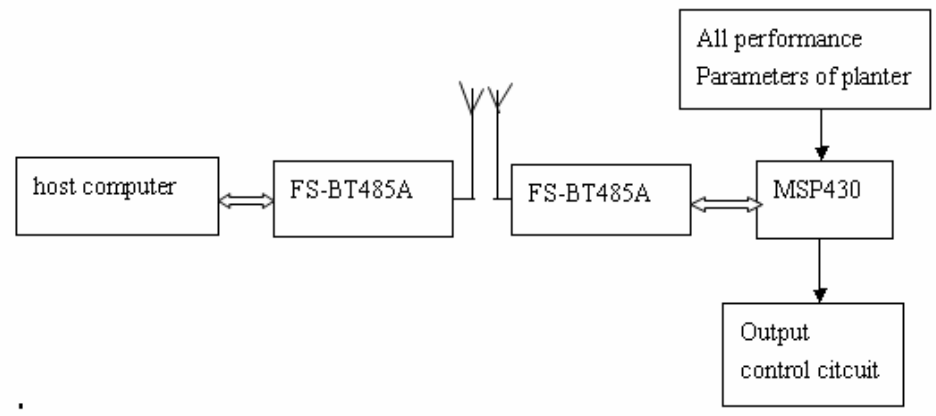

Fig. 7. The block diagram of the wireless data transmission system 


\section{Design of the Software System}

The function of the software system is:

To initialize the single-chip microcomputer and other chips;

to call data collection sub-program;

to call sound and light alarm sub-program when there is something wrong with the planter;

to detect whether the amount of sowing is appropriate;

to adjust the sowing speed and metering speed to keep them consistently;

to call the sound and light alarm sub-program;

to display the data on the LCD for the driver to watch or reference;

to analyze and store all the performance parameters;

to read the data on the hopper computer freely;

to call the sub-program of wireless data transmission.

The flow chart is showed in Fig. 8.

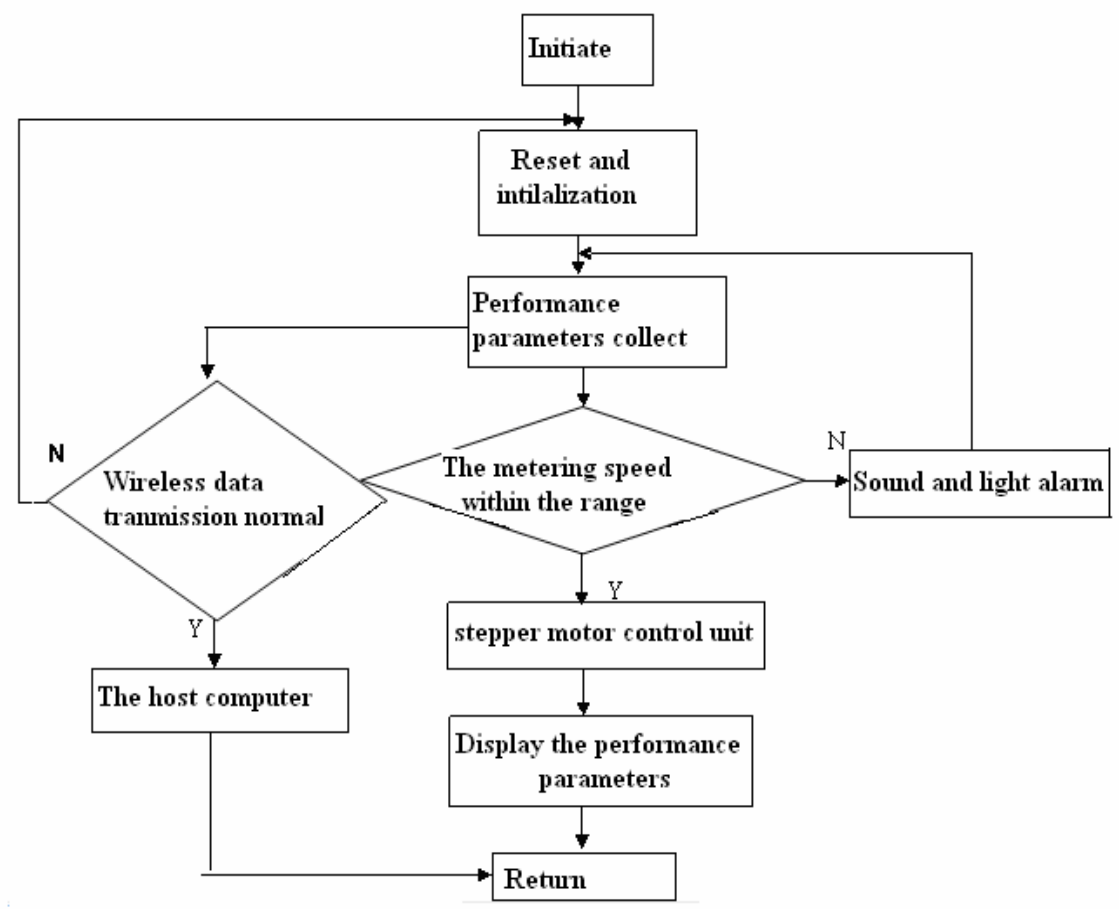

Fig. 8. Flow chart of the software system

\section{Experimental Test and Analysis}

Due to constraints, experiments are only conducted in the laboratory, and the experiments included data collection and alarm testing which were under artificial conditions. 
The materials used in this paper were the monitoring system for precision planter, infrared photoelectric sensors, Bluetooth device, PC, a stepper motor, some maize and wheat seeds.

In the test, the performance of the monitoring system could be tested by counting the number of seeds passing through the sensors and the number of chosen seeds before the test. At the same time, we could test the working conditions of the monitoring device by making some faults under artificial conditions. The results were showed in Table1.

Table 1. The test of the performance of the sound and alarm system

\begin{tabular}{|c|c|c|c|}
\hline Serial number & the test content & times & the datas(times) \\
\hline 1 & $\begin{array}{l}\text { blockage of the } \\
\text { furrow opener }\end{array}$ & 180 & $\begin{array}{l}\text { sound alarm } 180 \\
\text { light alarm } 180\end{array}$ \\
\hline 2 & seeds missed & 200 & sound alarm 200 \\
\hline 3 & stepper motor & 220 & $\begin{array}{l}\text { light alarm } 200 \\
\text { sound alarm } 220\end{array}$ \\
\hline & Stopping & & light alarm 220 \\
\hline
\end{tabular}

In the alarm test, the furrow opener and the metering devices were blocked 180 times and 200 times respectively. At the same time, the stepper motor was constantly started and stopped 220 times in the case of seeds presence. The results of alarm tests showed that the reliability of the alarm system was $100 \%$.

In the data collection tests, photoelectric sensors were used to detect the numbers of maize and wheat. The results were showed in table 2 .

Table 2. The results of the data collection test

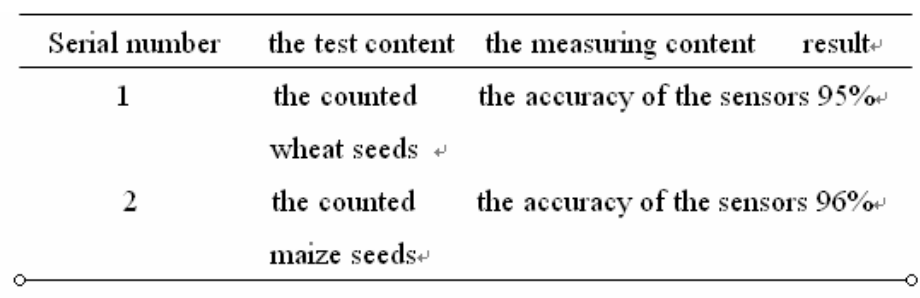

From the results, it could be concluded that the photoelectric sensors detected $95 \%$ wheat seeds and $96 \%$ maize seeds passing through it. It could be seen that the seeds detected were less than $100 \%$ because of the anti-dust properties and seed-tube coverage of the photoelectric sensor. And which reduced the precision and reliability of the monitoring system. So, it is necessary to improve the sensor's anti-dust ability and coverage of the seed tube. The following work is to solve these problems and this will improve the practical ability of the monitoring system. 


\section{Conclusions}

According to current domestic and international planter monitoring systems' status and development trends, combined the theory of automation and the information technology, a design scheme using single-chip computer as the control center and Bluetooth wireless transmission for the secondary was proposed. For the present situation of precision planter, the performance of the existing planter can not fully meet the requirements of agriculture, so it is necessary to design monitoring systems with better performance. First of all, the monitoring system should have better stability, reliability and universal property. Secondly, integrated monitoring system equipped with compensator should be designed based on the technologies of mechatronics and automatic control [12]. Monitoring system with automatic compensator is the main developing trend in the following years.

\section{References}

1. Singh, R.C., Singh, G., Saraswat, D.C.: Optimisation of Design and Operational Parameters of a Pneumatic Seed Metering Device for Planting Cottonseeds. Bio systems Engineering 92(4), 429-438 (2005)

2. Datta, R.K.: Development of Some Seeders with Particular Reference to Pneumatic Seed Drills. The Harvester, Indian Institute of Technology, Khargpur, India 16, $26-29$ (1974)

3. Zhang, X., Zhao, B.: Automatic Reseeding Monitoring System of Seed Drill. Transactions of CSAE 24, 119-123 (2008)

4. Hu, J., Li, X.: Magnetic Field Characteristic Analysis for the Magnetic Seed-metering Space of the Precision Seeder. Transactions of CSAE 21(12), 39-42 (2005)

5. Zhou, L., Zhang, X.: Monitor System of Precision Seeder Based on Capacitive Sensor. Journal of Agricultural Mechanization Research 11, 37-39 (2009)

6. Gong, L.: Development of Automatic Monitor System for Seed-cell Fill on Inside Precise Meter. Journal of Agricultural Mechanization Research 09, 47-49 (2008)

7. Dong, H., Zheng, J., Yang, J.: The Single-chip Control Applied in the Seeding-machine. Journal of Agricultural Mechanization Research 11, 181-184 (2006)

8. TI Corporation: MSP430 Universal synehronous Receive/Transfer communication interface. Taxes Instrument 1, 132-138 (1999)

9. Raju, M.: UltraLow Power RC Timer Implementation Using MSP430. Texas Instruments (2000)

10. Lee, W.: An efficient scheduling scheme for bluetooth scatternets using the sniff mode. In: Kahng, H.-K., Goto, S. (eds.) ICOIN 2004. LNCS, vol. 3090, pp. 103-113. Springer, Heidelberg (2004)

11. Petrioli, C., Basagai, S.: Degree-Constrained Multi-Hop Scatternet Formation for Bluetooth Networks. Mobile Networks and Applications 9(1), 33-47 (2004)

12. Xia, J., Zhou, Y., Zhang, P.: The Testing Technique Research of Seed Absence on Precise Seed-Meter Based on Virtual Instrument. Journal of Huazhong Agricultural University (Natural Science Edition) (04), 540-544 (2008) 